\title{
High Flow Nasal Oxygen therapy in a young pregnant patient with hypoxemic respiratory failure due to $\mathrm{H} 1 \mathrm{~N} 1$ influenza viral infection
}

\author{
KM Bopeththa ${ }^{\text {** }}$, V Pinto ${ }^{2}$, AI Herath ${ }^{3}$ \\ Registrar in Emergency Medicine ${ }^{I^{*}}$, Teaching Hospital, Kandy, Sri Lanka, Professor in Anaesthesiology \\ and Critical Care ${ }^{2}$, Department of Anaesthesiology, Faculty of Medicine, University of Peradeniya, Sri \\ Lanka, Senior Registrar in Anaesthesiology and Intensive Care ${ }^{3}$, Teaching Hospital, Peradeniya, Sri \\ Lanka.
}

\begin{abstract}
Pregnant women are at high risk of infection with the novel H1N1 influenza A virus. A 30-year-old pregnant woman at 35 weeks of gestation was admitted with acute onset fever, cough and shortness of breath with hypoxaemic respiratory failure. Laboratory investigations confirmed influenza A infection. This case report illustrates how High Flow Nasal Oxygen device gave good results in hypoxemic respiratory failure especially in the setting of possible unexpected infections and ventilator associated pneumonia.
\end{abstract}

Keywords: H1N1 influenza; high flow nasal device; oxygen therapy; modes of ventilation

\section{Introduction}

Pregnancy and postpartum period are considered increased risk factors for hospitalization, ICU admission, delayed recovery and death following H1N1 Influenza viral infection. World Health Organization says globally there is a decreasing trend in seasonal influenza. In tropical Asia, the trend is same. There are no recent data available from Sri Lanka, but cases of influenza continue to be reported from all areas of the country.

High Flow Nasal Oxygen device, a new respiratory therapeutic technique which provides warmed humidified high flow oxygen through a nasal cannula is used in patients with hypoxemic respiratory failure. The high flows (e.g. 50L) match with the patient's peak inspiratory flow rates.

In addition, it reduces anatomical dead space and creates a positive pressure in upper airways. Studies

\section{*Correspondence: KM Bopeththa E mail: kameerabvkm@gmail.com}

iD https://orcid.org/0000-0002-8788-0682

Received:30/08/2017

Accepted: 09/10/2017

DOI: http://doi.org/10.4038/slja.v26i1.8273

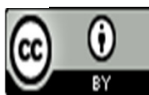

demonstrated that High Flow Nasal Device (HFND) provides better oxygenation when compared with conventional face masks and nasal cannulas. ${ }^{1}$

\section{Case Presentation}

A $30 \mathrm{yr}$ old woman in her second pregnancy presented at 35 weeks period of gestation with a 6day history of high grade fever, non-productive cough and shortness of breath to Base hospital, Mawanella, Sri Lanka. First pregnancy had been an emergency cesarean section due to foetal distress. She had been in good health throughout this pregnancy, gave no history of travels or exposure to anyone with probable influenza. She had no chronic medical issues and did not smoke. She was not vaccinated against influenza.

On admission, she was reported to have respiratory distress with peripheral oxygen saturation $\left(\mathrm{SpO}_{2}\right)$ of $85 \%$. She was transferred to intensive care unit (ICU) Teaching Hospital, Peradeniya. On arrival, she was conscious, rational with Glasgow coma scale of 15 . She was febrile and tachypnoeic at 40breaths/minute. Chest examination revealed bibasal reduced breath sounds with rhonchi and coarse crepitations. $\mathrm{SpO}_{2}$ on air was $85 \%$. Her HR was $127 \mathrm{beats} / \mathrm{minute}$ and $\mathrm{BP}$ was $112 / 64 \mathrm{mmHg}$. Abdominal examination revealed a single live fetus. Arterial blood gas analysis (ABG) showed pH:7.42, $\quad \mathrm{PaO}_{2}: 56 \mathrm{mmHg}, \quad \mathrm{PaCO}_{2}: 25 \mathrm{mmHg}$, $\mathrm{HCO}_{3} \mathrm{Std}: 19.5 \mathrm{mmol} / \mathrm{L}$, BEecf: $-8.3, \mathrm{SO}_{2}: 89 \%$ and 
lactate: $0.6 \mathrm{mmol} / \mathrm{L}$. Initial laboratory investigations included white blood cells (WBC): 6.4 cells $/ \mathrm{L}^{3}$, neutrophils: $64 \%$, lymphocytes:32\%, haemoglobin: $11.9 \mathrm{~g} / \mathrm{dL}$, platelets: 148 cells/ $\mathrm{L}^{3}, \mathrm{C}$ - reactive protein (CRP): $70.6 \mathrm{mg} / \mathrm{dL}$, alanine transaminase (ALT): 41U/L, aspartate transaminase (AST):89U/L, Serum sodium: $139 \mathrm{mmol} / \mathrm{L}$, potassium: $4.4 \mathrm{mmol} / \mathrm{L}$, international normalized ratio (INR):1.02, respiratory secretions positive for Influenza A. Chest $\mathrm{X}$ ray showed bilateral alveolar infiltrates involving middle and lower zones. The tentative diagnosis of $\mathrm{H} 1 \mathrm{~N} 1$ or community acquired pneumonia was made.

She was given $60-80 \%$ oxygen via a face mask with reservoir bag. Oral oseltamivir $150 \mathrm{mg}$ twice daily, intravenous ceftriaxone $2 \mathrm{~g}$ twice daily with oral clarithromycin $500 \mathrm{mg}$ twice daily was started. Regular nebulizations with bronchodilators, deep vein thrombosis prophylaxis with pneumatic compression device and enoxaparin s.c. was provided. Regular obstetric team visits ensured proper foetal wellbeing. Her haemodynamic parameters were maintained throughout the ICU stay.

On the second day although she remained tachypnoeic, her ABG showed improvement in oxygenation as $\mathrm{pH}$ : 7.33, $\mathrm{PaO}_{2}: 121 \mathrm{mmHg}, \mathrm{PaCO}_{2}$ : 23mmHg. Temperature had settled. 2D echocardiogram revealed good cardiac function. US chest revealed no pleural effusions.

Following multidisciplinary meeting it was decided to deliver the baby by urgent cesarean section. Lower segment cesarean section was performed under combined spinal epidural anaesthesia. Throughout the surgery CPAP with $70 \%$ oxygen (PEEP $5 \mathrm{mmHg}$ and Pressure support $10 \mathrm{mmHg}$ ) was continued. Intraoperative period was uneventful and $1.8 \mathrm{~kg}$ healthy baby was delivered and sent to premature baby unit for observation. Post operative analgesia was provided via epidural route.

On the $3^{\text {rd }}$ day of ICU stay, fever recurred and there was a drop in arterial oxygenation. $\mathrm{ABG}$ revealed pH: 7.49, $\mathrm{PaO}_{2}: 84 \mathrm{mmHg}, \mathrm{PaCO}_{2}: 36 \mathrm{mmHg}$ with saturation around $97 \%$. Even though there was no significant clinical deterioration, her chest $\mathrm{X}$ ray revealed extension of alveolar infiltrates towards the apices. CPAP was continued with same settings.

Because of worsening tachypnoea and deteriorating arterial blood gases need for intubation was discussed. Patient was started on High Flow Nasal Device (HFND) with $70 \%$ oxygen $(45 \mathrm{~L} / \mathrm{min})$. The tolerability and patient's comfort improved with HFND. She was able to express herself, take oral feeds and start on breathing exercises while continuing HFND.

On the $4^{\text {th }}$ day she became afebrile. Sputum culture revealed pseudomonas growth which was sensitive to meropenum. Urine culture showed growth of Candida albicans. Because of positive cultures antibiotics were changed to intravenous meropenum and oral fluconazole was started for candidiasis. Mycoplasma serology, sputum for fungal studies and blood cultures were negative. Procalcitonin level revealed no evidence of sepsis. Respiratory parameters remained static and ABG showed pH:7.45, $\mathrm{PaO}_{2}: 91 \mathrm{mmHg}, \mathrm{PaCO}_{2}: 39 \mathrm{mmHg}$.

On $5^{\text {th }}$ day, respiratory support was continued via HFND with $60 \%$ oxygen. Respiratory rate (RR) remained around 35-40 breaths/min. Although she had a mild fever spike, her WBC count was 8.4 cells $/ \mathrm{L}^{3}$ with neutrophils $70 \%$ and lymphocytes $26 \%$. CRP came down to $50 \mathrm{mg} / \mathrm{dl}$. ABG showed some improvement in oxygenation with $\mathrm{pH}$ : 7.48, $\mathrm{PaO}_{2}: 101 \mathrm{mmHg}, \mathrm{PaCO}_{2}: 36 \mathrm{mmHg}, \mathrm{SO}_{2}: 99 \%$.

On $6^{\text {th }}$ day, she showed significant clinical improvement in respiratory parameters. Her RR was 30-35breaths/minute. ABG showed significant improvement in oxygenation, $\mathrm{pH}$ : 7.45, $\mathrm{PaO}_{2}$ : $120 \mathrm{mmHg}, \mathrm{PaCO}_{2}: 38 \mathrm{mmHg}$. We reduced inspired oxygen concentration via HFND to $50 \%$.

On $7^{\text {th }}$ day patient's arterial blood gases revealed pH: $7.44, \mathrm{PaCO}_{2}: 38 \mathrm{mmHg}$ and $\mathrm{PaO}_{2}: 118 \mathrm{mmHg}$. Then HFND was replaced with $40 \%$ venturi face mask and as she was stable, sent to High Dependency Unit. She continued to recover and supplemental oxygen was tailed off. Oseltamivir was continued for 10 days and intravenous antibiotics for 14 days. During her hospitalization haemodynamic parameters, liver and renal functions were stable. She was discharged on the $22^{\text {nd }}$ day with her newborn. 


\section{Discussion}

Obstetric patients in the $2^{\text {nd }}$ or $3^{\text {rd }}$ trimester and who are 2 weeks or less post-partum are most at risk of developing complications of $\mathrm{H} 1 \mathrm{~N} 1$ virus infection including increased risk of hospital admission, ICU stay and death. Reported overall case fatality was less than $0.5 \%$ and approximately $9 \%-31 \%$ of hospitalized patients were admitted to an ICU, where $14 \%-46 \%$ of died. ${ }^{2}$

Complications of $\mathrm{H} 1 \mathrm{~N} 1$ influenza infection includes severe pulmonary complications, bacterial co-infection, exacerbation of underlying chronic disease and miscellaneous conditions including myositis, rhabdomyolysis and central nervous complications. Pulmonary complications include severe hypoxemia and ARDS. ${ }^{3}$

This case report illustrates how non-invasive HFND gave good results in hypoxemic respiratory failure due to influenza H1N1 infection especially in the setting of possible unexpected infections and ventilator associated pneumonia. HFND has several physiological advantages over traditional oxygen therapy devices, including decreased nasopharyngeal resistance, washout of nasopharyngeal dead space, generation of positive pressure in the pharynx, increasing alveolar recruitment, humidification of airways, increased fraction of inspired oxygen and improved mucociliary clearance. ${ }^{4.5}$ HFND was also associated with a higher partial pressure of arterial oxygen $(\mathrm{PaO} 2)$ and lower respiratory rate. ${ }^{5}$

HFND is most suitable in conditions of hypoxemic non hypercarbic situations. These patients usually need high fractional inspired oxygen concentration with high inspiratory flow rates. Traditional conventional devices like nasal prongs, face masks can only provide maximum flow rates up to $15 \mathrm{~L} /$ minute and fractional inspired oxygen concentration not more than 40-55\%. HFND can provide $100 \%$ humidified heated oxygen at a maximum flow rate of $60 \mathrm{~L} / \mathrm{min} .{ }^{6}$ It is better tolerated and more comfortable compared to traditional methods. ${ }^{7}$

Although HFND is a supportive therapeutic technique, enhanced respiratory support with this novel device can save lives with very minimal complications.

\section{References}

1. Sotello D, Rivas M, Mulkey Z, Nugent K. HighFlow Nasal Cannula Oxygen in Adult Patients: A Narrative Review. The American Journal of the Medical Sciences. 2015; 349(2):179-185. https://doi.org/10.1097/MAJ.0000000000000345 PMid:25285514

2. ICU management of Pandemic (H1N1) Influenza Anaesthesia Tutorial of The Week 209. 2017.

3. CDC. Intensive Care Patients with Severe Novel Influenza A (H1N1) virus infection - Michigan, June 2009, MMMR Morb Mort Wkly Rep. 2009; 58: 749- 752 .

4. Groves $\mathrm{N}$ and Tobin A. High flow nasal oxygen generates positive airway pressure in adult volunteers. AustCrit Care 2007; 20: 126-131. https://doi.org/10.1016/j.aucc.2007.08.001 PMid:17931878

5. Mo“ ller W, Celik G, Feng S, et al. Nasal high flow clears anatomical dead space in upper airway models.JApplPhysiol(1985)2015;118:1525-1532. https://doi.org/10.1152/japplphysiol.00934.2014 PMid:25882385 PMCid:PMC4482836

6. Roca O, Riera J, Torres F, et al. High-flow oxygen therapy in acute respiratory failure.Respir Care 2010;55:408-413. PMid:20406507

7. Parke RL, Eccleston ML and McGuinness SP. The effects of flow on airway pressure during nasal highflow oxygen therapy. Respir Care 2011;56:11511155. https://doi.org/10.4187/respcare.01106 PMid:21496369 